\title{
Near Infrared Absorption Spectra of Deuterated Acetylene
}

\author{
Earle K. Plyler and Norman Gailar
}

\begin{abstract}
The bands of $\mathrm{C}_{2} \mathrm{D}_{2}$ at 1.96 and 2.39 microns have been measured under high resolution so that the moments of inertia of this molecule could be compared with that of $\mathrm{C}_{2} \mathrm{H}_{2}$ and $\mathrm{C}_{2} \mathrm{HD}$. From the measurement of the rotational structure the ground rotational constant, $B_{G}$, is found to be $0.8471 \mathrm{~cm}^{-1}$. The center of the $\omega_{1}+\omega_{3}$ band is $5097.07 \mathrm{~cm}^{-1}$, and the center of $\omega_{2}+\omega_{3}$ is $4190.46 \mathrm{~cm}^{-1}$.
\end{abstract}

The absorption spectra of $\mathrm{C}_{2} \mathrm{H}_{2}$ and of $\mathrm{C}_{2} \mathrm{HD}$ have been studied in detail, and internuclear distances have been calculated. ${ }^{1}$ Inasmuch as further comparisons can be made by a study of $\mathrm{C}_{2} \mathrm{D}_{2}$, an investigation in the near infrared has been made of this molecule. In the course of this study the results of a similar investigation were made known by Talley and Nielsen. ${ }^{2}$ Their $B_{0}$ will be compared with ours.

For a given vibrational state, linear molecules have a single moment of inertia, and their rotational fine structure is composed of a series of nearly equally spaced lines. By a comparison of the moments of inertia of the three acetylenes the $\mathrm{C}-\mathrm{H}$ and $\mathrm{C}-\mathrm{D}$ distances are, theoretically, calculable. In order to calculate these distances to one part in 10,000 , it is required to measure the rotational lines to $0.03 \mathrm{~cm}^{-1}$ in the $2-\mu$ region. To approach such accuracy a high resolution instrument that would reproduce spectra faithfully would be required.

These measurements were made on an infrared grating spectrometer, which was constructed at the National Bureau of Standards. A lead sulfide cell was used as the detecting element. The grating was ruled at Johns Hopkins University in the aluminum film on an optically flat quartz blank 9 in. in diameter. The spacing was 15,000 lines/in., and the lines, about 5 in. long, extended over $7 \frac{1}{2}$ in. The grating produces very sharp images and is almost free of ghosts. The precision slits and cone bearings for the grating were constructed in the physics shop of the University of Michigan.

The spectrometer with the cover removed is shown in figure 1. In front of the entrance slit is a chopper, which modulates the radiant energy 1,080 times a second. The amplifier is a narrow band pass type and has been described by Nelson and Wilson. ${ }^{3}$ The detector is a $\mathrm{PbS}$ cell, and with the present arrangement the resolution is about $0.1 \mathrm{~cm}^{-1}$ at $2 \mu$. The optical system is of the conventional design. The radiant energy from the entrance slit, $S_{1}$, falls on an off-axis paraboloidal mirror, $M_{1}$, which is 7 in. in diameter and $102 \mathrm{~cm}$ in focal length. The mirror is $10^{\circ}$ off axis and allows the grating, $G$, to be mounted sufficiently to the side so as not to intercept the incident beam. After the parallel beam

1 G. Herzberg, Infrared and Raman spectra of polyatomic molecules, p. 290 to 292 (D. Van Nostrand Co., New York, N. Y., 1945)

2 R. M. Talley and A. H. Nielsen, Bul. APS 26, 51 (Feb. 1, 1951)

3 R. C. Nelson and W. R. Wilson, Proc. Nat. Elec. Conf. 3, (1947) falls on the grating, different wavelengths, depending on the grating position, are diffracted back to the paraboloidal mirror. Then this energy is focused on the second slit, $S_{2}$, by means of a small plane mirror set at $45^{\circ}$ to the impinging beam. After the energy passes through the second slit, another plane mirror is used to cause the radiation to fall on the ellipsoidal mirror, $M_{2}$, which focuses the image of the second slit on the $\mathrm{PbS}$ cell, $D$. The image is greatly reduced in size because of the 7 to 1 ratio of the foci of the ellipsoidal mirror.

The source of the energy is a tungsten ribbon filament lamp, drawing about $37 \mathrm{amp}$ and operating: at about $2,700^{\circ} \mathrm{K}$.

The grating is mounted on a cone bearing and is rotated by means of a worm and gear. Reduction gears allow the spectrum to be scanned at four different speeds. A microswitch, operated by the teeth of one of these gears, activates a pen of the recorder, which places fiducial marks at constant angular intervals. The spectrum is recorded by a Leeds \& Northrup Speedomax, type A. Weights are hung on the recorder paper to provide constant tension. The spectrometer is calibrated by superimposing on the record appropriate emission lines known to an accuracy of $\pm 0.01 \mathrm{~A}$ or better.

In the $2-\mu$ region this instrument can resolve lines separated by slightly less than $0.1 \mathrm{~cm}^{-1}$ when the slit width is $0.02 \mathrm{~mm}$. The centers of absorption lines, when reasonably strong, are reproduced in successive

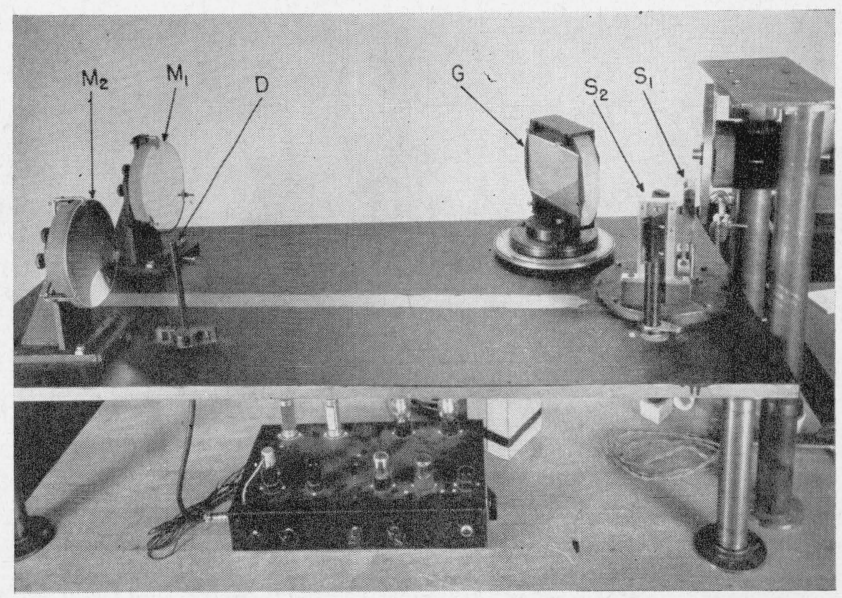

FIGURE 1. Granting spectrometer.

The letters refer to the various elements of the instrument. 
runs to about $0.1 \mathrm{~cm}^{-1}$. This will permit calculation of the moment of inertia of $\mathrm{C}_{2} \mathrm{D}_{2}$ to 1 part in 4,000 , but will not allow the detection of any small difference that may exist between the $\mathrm{C}-\mathrm{D}$ and the $\mathrm{C}-\mathrm{H}$ distances.

The deuterated acetylene, 3 liters at atmospheric pressure, was obtained from the Atomic Energy Commission. Mass spectrograph tests at the Bureau shew that about 94 percent of the gas was $\mathrm{C}_{2} \mathrm{D}_{2}$. The balance was $\mathrm{C}_{2} \mathrm{HD}$ and $\mathrm{C}_{2} \mathrm{H}_{2}$. The gas was placed in a $60-\mathrm{cm}$ cell with windows of glass. The cell was made from a brass tube $8 \mathrm{~cm}$ in diameter.

In analyzing the spectrum of a molecule such as $\mathrm{C}_{2} \mathrm{D}_{2}$, the ideal procedure would be to study several bands either originating in or ending in a common state averaging the results of several measurements of each band, to minimize random errors. In the present work several factors, short cell lengths, the explosive quality of compressed acetylene, and the limited range of the $\mathrm{PbS}$ detector, limited the number of bands that could be used to two. The $\omega_{1}+\omega_{3}$ band at $1.96 \mu$ was measured four times, and the $\omega_{2}+\omega_{3}$ band at $2.39 \mu$ was measured five times. Each band was measured at several pressures and several grating speeds.

To find the rotational constants and moments of inertia, use was made of the well known relations ${ }^{4}$

$$
\Delta_{2} F(J)=R(J-1)-P(J+1)=4 B^{\prime \prime}(J+1 / 2)-8 D(J+1 / 2)^{3}
$$

$$
R(J)+P(J)=2 \nu_{0}+2 B^{\prime}+2\left(B^{\prime \prime}-B^{\prime}\right) J^{2} .
$$

When $D$ is negligibly small, $B^{\prime \prime}$, the lower state

${ }^{4}$ G. Herzberg, Infrared and Raman spectra of polyatomic molecules, chap. IV (D. Van Nostrand Co., New York, N. Y., 1945) rotational constant, can be obtained from the slope of the straight line that results when $\Delta_{2} F(J)$ is plotted against J. $B^{\prime}-B^{\prime \prime}$, the difference between the rotational constants of the upper and lower states, can be found in an analogous manner, as can $\nu_{0}$, the band origin.

When eq 1 is plotted a straight line results, the slope of which is about $3.5 \mathrm{~cm}^{-1}$. This approximate value is now used in the plot of $\Delta_{2} F(J)-3.5(J+1 / 2)$ against $J$. This, too, results in a straight line of slope $m$, and $B^{\prime}$ can be found from the relation

$$
B^{\prime}=(3.5-m) / 4
$$

The results of this investigation are presented in figures 2 to 4 and in table 1 . Figure 2 is a reproduction of the $\omega_{2}+\omega_{3}$ band (with three of the kyrpton emission lines that establish the calibration). The intensity of the absorption lines of $\mathrm{C}_{2} \mathrm{D}_{2}$ shows the $2: 1$ alternation pattern expected of molecules that follow Bosé statistics. Faint indications can be seen of a superimposed band of a higher state. Figure 3 is a reproduction of the $\omega_{1}+\omega_{3}$ band. Two $\mathrm{C}_{2} \mathrm{HD}$ bands $^{5}$ are present and prevent the $2: 1$ intensity ratio from being observed. In the $P$ branch, however, at $J=19$ to 24 this intensity ratio is noticeable.

In analyzing the spectra, values of $\Delta_{2} F(J)$ from the nine records were averaged and the results are tabulated in column 1 of table 1 . This average value, divided by $J+\frac{1}{2}$, appears in column 2 . Column 3 presents the value of $\Delta_{2} F(J)-3.5\left(J+\frac{1}{2}\right)$. Figure 4 is a plot of this value against $J$. Two lines are drawn through the values of $\Delta_{2} F(J)-3.5\left(J+\frac{1}{2}\right)$ representing the minimum and maximum probable slope. Line $A$ results in $B_{0}=0.8470 \mathrm{~cm}^{-1}$; line $B$ in $B_{0}=0.8473 \mathrm{~cm}^{-1}$. Taking the mean of the values ${ }_{5}$ F. Stitt, J. Chem Phys. 8, 56 (1940).

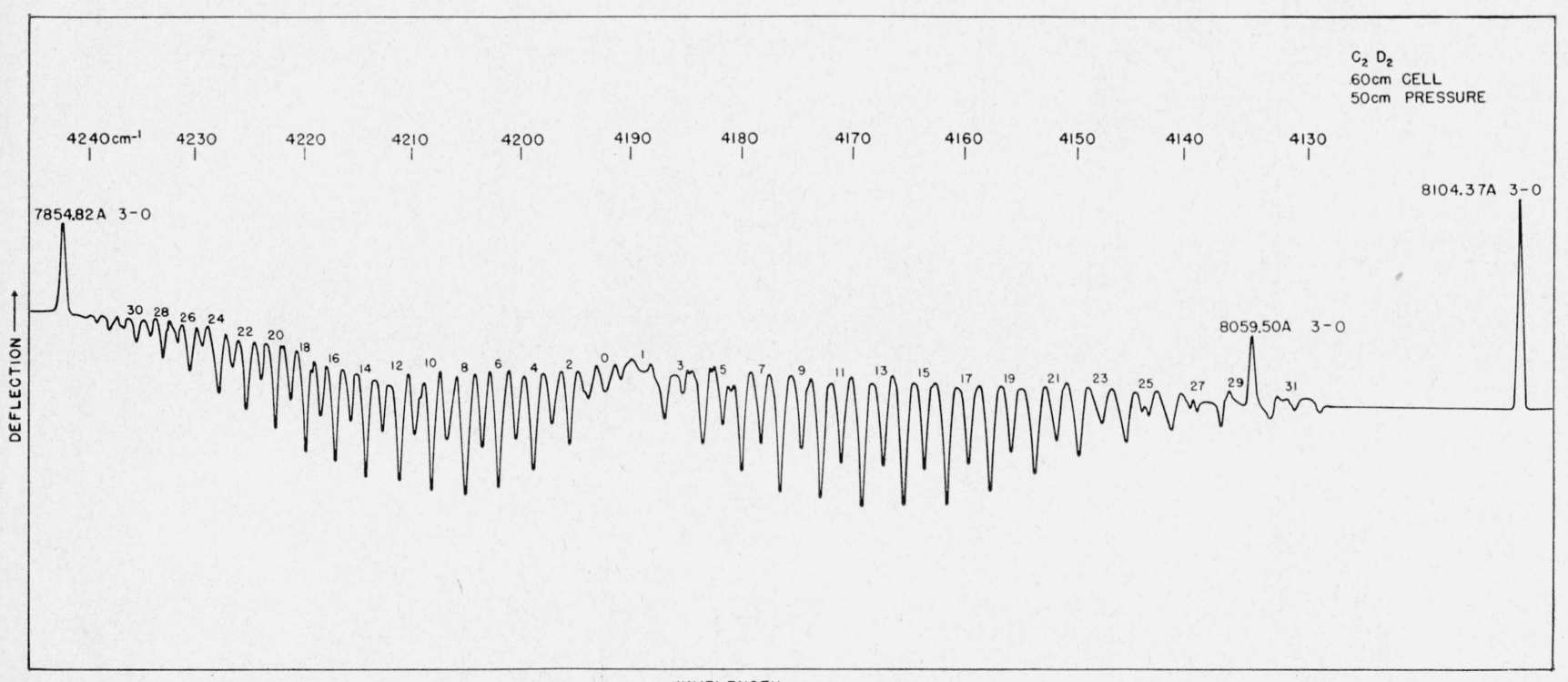

WAVELENGTH $\longrightarrow$

FigURE 2. Absorption spectrum of the $\omega_{2}+\omega_{3}$ band of $C_{2} D_{2}$ at $2.39 \mu, \nu_{0}=4190.46 \mathrm{~cm}^{-1}$.

The numbers accompanying the various absorption lines are the $J$ numbers of the lines. The three emission lines are Kr lines. 


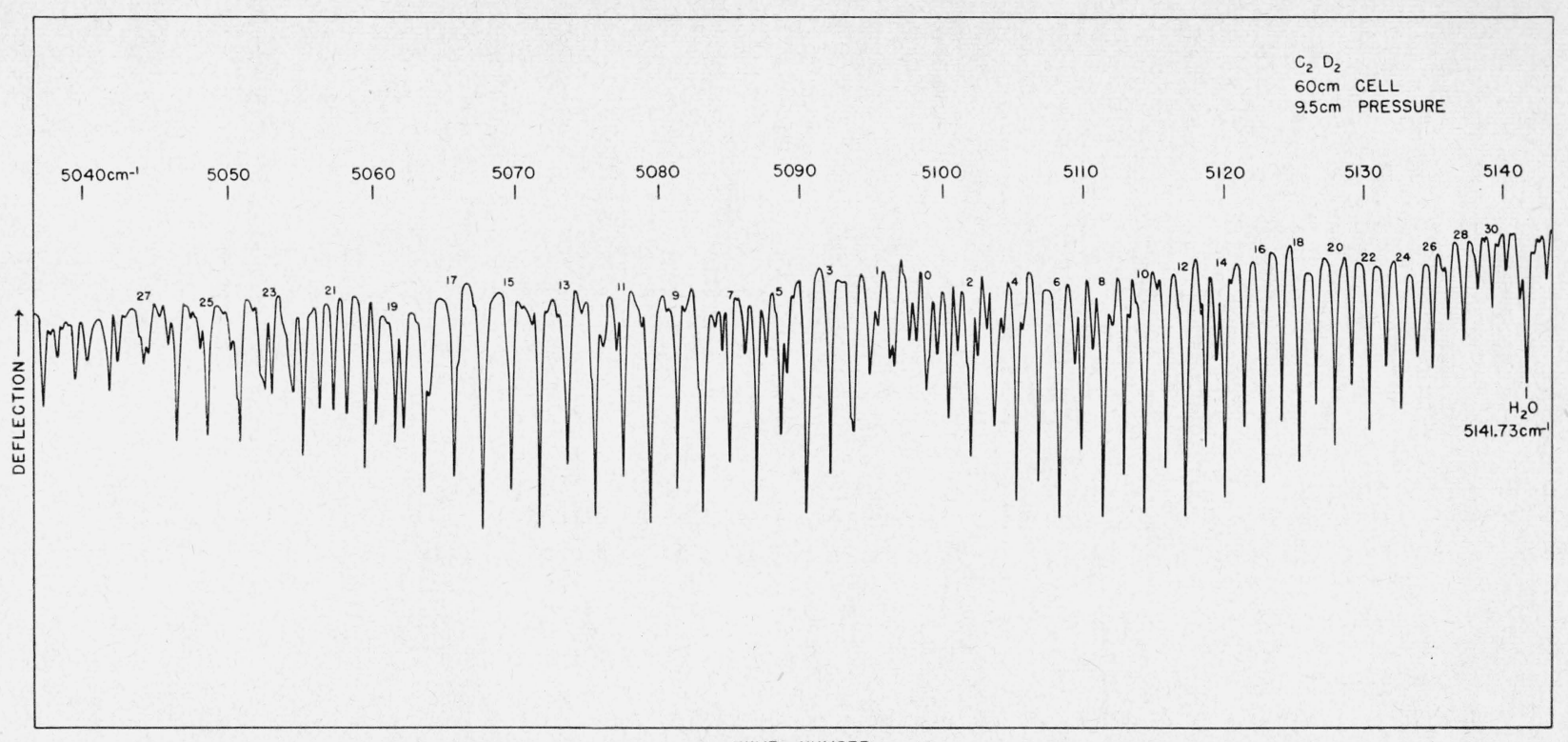

WAVE NUMBER $\longrightarrow$

Figure 3. Absorption spectrum of the $\omega_{1}+\omega_{3}$ band of $\mathrm{C}_{2} \mathrm{D}_{2}$ at $1.96 \mu, \nu_{0}=5097.07 \mathrm{~cm}^{-1}$.

The numbers accompanying the various absorption lines are the $J$ numbers of the lines:

TABLE 1. Measured values of quantities used in determination of $B_{0}$ for the $J$ values from 1 through 30

\begin{tabular}{|c|c|c|c|c|}
\hline$J$ & $\begin{array}{c}\overline{\Delta_{2} F(J)}= \\
\text { Average } \\
R(J-1)- \\
P(J+1)\end{array}$ & $\overline{\frac{\Delta_{2} F(J)}{J+\frac{1}{2}}}$ & $\begin{array}{c}\Delta \nu= \\
\Delta_{2} F(J)- \\
3.5\left(J+\frac{1}{2}\right)\end{array}$ & $\begin{array}{c}\Delta \nu- \\
\text { average } \Delta \nu\end{array}$ \\
\hline $\begin{array}{l}1 \\
2 \\
3 \\
4 \\
5\end{array}$ & $\begin{array}{r}c m^{-1} \\
5.11 \\
8.50 \\
11.90 \\
15.31 \\
18.66\end{array}$ & $\begin{array}{l}c m^{-1} \\
\text { 3. } 407 \\
3.400 \\
3.400 \\
3.402 \\
3.393\end{array}$ & $\begin{array}{r}c m^{-1} \\
-0.14 \\
-.16 \\
-.35 \\
-.44 \\
-.59\end{array}$ & $\begin{array}{r}c m^{-1} \\
-0.02 \\
+.09 \\
0 \\
+.04 \\
+.01\end{array}$ \\
\hline $\begin{array}{r}6 \\
7 \\
8 \\
9 \\
10\end{array}$ & $\begin{array}{l}22.01 \\
25.34 \\
28.79 \\
32.15 \\
35.54\end{array}$ & $\begin{array}{l}\text { 3. } 386 \\
\text { 3. } 379 \\
\text { 3. } 387 \\
\text { 3. } 384 \\
\text { 3. } 385\end{array}$ & $\begin{array}{l}-.74 \\
-.91 \\
-.96 \\
-1.10 \\
-1.21\end{array}$ & $\begin{array}{l}-.04 \\
-.10 \\
0 \\
-.04 \\
-.04\end{array}$ \\
\hline $\begin{array}{l}11 \\
12 \\
13 \\
14 \\
15\end{array}$ & $\begin{array}{l}38.95 \\
42.39 \\
45.70 \\
49.13 \\
52.49\end{array}$ & $\begin{array}{l}\text { 3. } 387 \\
\text { 3. } 391 \\
\text { 3. } 385 \\
\text { 3. } 388 \\
\text { 3. } 386\end{array}$ & $\begin{array}{l}-1.30 \\
-1.36 \\
-1.55 \\
-1.62 \\
-1.76\end{array}$ & $\begin{array}{l}0 \\
+.04 \\
+.02 \\
+.01 \\
0\end{array}$ \\
\hline $\begin{array}{l}16 \\
17 \\
18 \\
19 \\
20\end{array}$ & $\begin{array}{l}55.91 \\
59.32 \\
62.65 \\
66.05 \\
69.44\end{array}$ & $\begin{array}{l}\text { 3. } 388 \\
\text { 3. } 390 \\
\text { 3. } 386 \\
\text { 3. } 387 \\
\text { 3. } 387\end{array}$ & $\begin{array}{l}-1.84 \\
-1.93 \\
-2.10 \\
-2.20 \\
-2.31\end{array}$ & $\begin{array}{c}+.01 \\
+.04 \\
+.01 \\
0 \\
+.01\end{array}$ \\
\hline $\begin{array}{l}21 \\
22 \\
23 \\
24 \\
25\end{array}$ & $\begin{array}{l}72.89 \\
76.20 \\
79.64 \\
83.04 \\
86.31\end{array}$ & $\begin{array}{l}\text { 3. } 390 \\
\text { 3. } 387 \\
\text { 3. } 389 \\
\text { 3. } 389 \\
\text { 3. } 385\end{array}$ & $\begin{array}{l}-2.36 \\
-2.55 \\
-2.61 \\
-2.71 \\
-2.94\end{array}$ & $\begin{array}{l}+.08 \\
0 \\
+.06 \\
-.04 \\
-.04\end{array}$ \\
\hline $\begin{array}{l}26 \\
27 \\
28 \\
29 \\
30\end{array}$ & $\begin{array}{r}89.78 \\
93.07 \\
96.46 \\
99.84 \\
103.22\end{array}$ & $\begin{array}{l}\text { 3. } 388 \\
\text { 3. } 384 \\
\text { 3. } 384 \\
\text { 3. } 384 \\
\text { 3. } 384\end{array}$ & $\begin{array}{l}-2.62 \\
-3.18 \\
-3.29 \\
-3.41 \\
-3.53\end{array}$ & $\begin{array}{l}+.40 \\
-.06 \\
-.04 \\
-.05 \\
-06\end{array}$ \\
\hline
\end{tabular}

of $\Delta_{2} F(\boldsymbol{J}) /\left(\boldsymbol{J}+\frac{1}{2}\right)$ in column 2 of table 1 yields a value of $B_{0}=0.8469 \mathrm{~cm}^{-1}$. Averaging these three values of $B_{0}$ gives the results $B_{0}=0.8471 \pm 0.0003$ $\mathrm{cm}^{-1}$. Column 4 of table 1 shows the deviation of the individual values of $\Delta_{2} F(J)-3.5\left(J+\frac{1}{2}\right)$ from the values indicated by the resultant $B_{0}=0.8471 \mathrm{~cm}^{-1}$. This value can be compared with that of $B_{0}=$

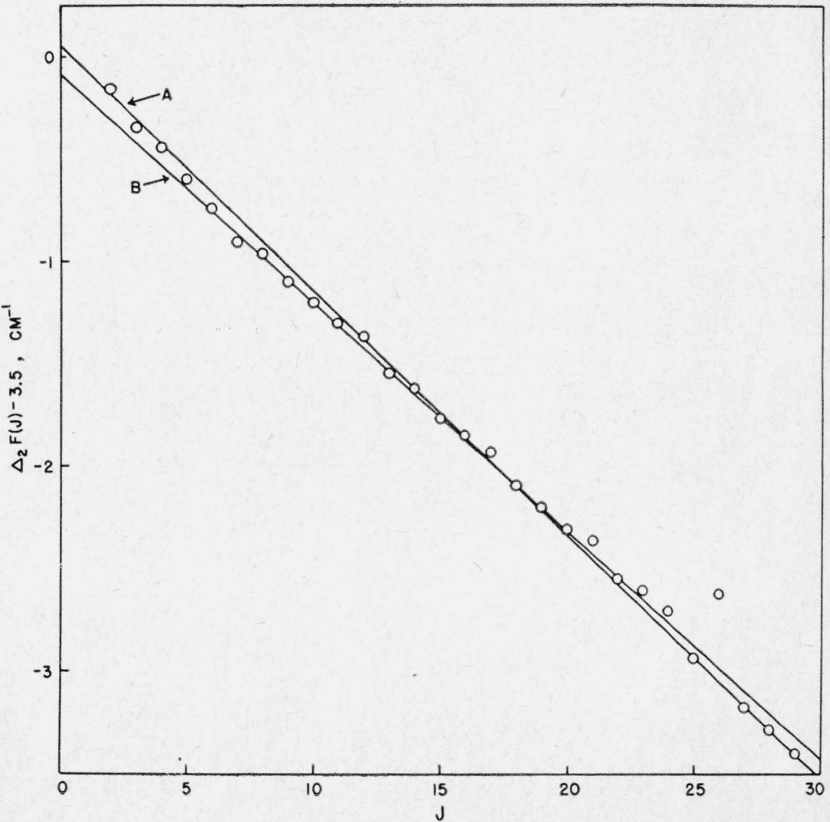

Figure 4. Plot of $\Delta_{2}(J)-3.5(J+1 / 2)$ as a function of $J$ values.

Lines $\mathrm{A}$ and $\mathrm{B}$ are the minimum and maximum probable slopes.

$0.84827 \mathrm{~cm}^{-1}$ reported by Talley and Nielsen (see footnote 2 ).

To calculate internuclear distances, the value of $B_{e}$, the equilibrium rotation constant, is necessary. From $B_{e}$ can be found the various $r_{e}^{\prime} \mathrm{s}$, the equilibrium distances. To find $B_{e}$, however, each normal mode must be represented at least once in the bands studied; we cannot find $B_{e}$ from the two bands studied. 
The equilibrium distances $\mathrm{C}-\mathrm{H}$ and $\mathrm{C}-\mathrm{D}$ should be equal, with a slight variance for the zero-order state. If this variance is ignored, the zero-order distances reported by Herzberg (see footnote 3) can be used to calculate a $B_{0}$. This has a value of $0.8474 \mathrm{~cm}^{-1}$.

Again ignoring the difference between $r_{0}$ of $\mathrm{C}-\mathrm{H}$ and $r_{0}$ of $\mathrm{C}-\mathrm{D}$, our value of $B_{0}$ can be combined with that for $\mathrm{C}_{2} \mathrm{H}_{2}$ of Herzberg (see footnote 3 ) to find the internuclear zero state distances. The values of the distances are $\mathrm{C}-\mathrm{D}$ and $\mathrm{C}-\mathrm{H}=$ $1.0611 \times 10^{-8} \mathrm{~cm}$, and $\mathrm{C} \equiv \mathrm{C}=1.2067 \times 10^{-8} \mathrm{~cm}$. Combining the $B_{0}$ of $\mathrm{C}_{2} \mathrm{HD}$ of Herzberg (see footnote 3) with our $\mathrm{C}_{2} \mathrm{D}_{2}$ value gives $\mathrm{C}-\mathrm{H}$ and $\mathrm{C}-\mathrm{D}$ $=1.0630 \times 10^{-8} \mathrm{~cm}$ and $\mathrm{C} \equiv \mathrm{C}=1.2054 \times 10^{-8} \mathrm{~cm}$. When the values of the constants of $\mathrm{C}_{2} \mathrm{H}_{2}$ and $\mathrm{C}_{2} \mathrm{HD}$ are used, one finds $\mathrm{C}-\mathrm{H}$ and $\mathrm{C}-\mathrm{D}=1.0595 \times 10^{-8}$ $\mathrm{cm}$ and $\mathrm{C} \equiv \mathrm{C}=1.2073 \times 10^{-8} \mathrm{~cm}$. Theoretically, the rotational constants of $\mathrm{C}_{2} \mathrm{H}_{2}, \mathrm{C}_{2} \mathrm{HD}$, and $\mathrm{C}_{2} \mathrm{D}_{2}$ can be used to solve for the values of the three internuclear distances $\mathrm{C} \equiv \mathrm{C}, \mathrm{C}-\mathrm{H}$, and $\mathrm{C}-\mathrm{D}$; unfortunately, the precision of measurement of these constants is not sufficient to detect any differences between $\mathrm{C}-\mathrm{H}$ and $\mathrm{C}-\mathrm{D}$ distances.

The upper state rotational constants were found by plotting eq 2 . They are:

$$
\begin{gathered}
B_{10100}=0.8574 \pm 0.0003 \mathrm{~cm}^{-1} ; \\
B_{01100}=0.8547 \pm 0.0003 \mathrm{~cm}^{-1} .
\end{gathered}
$$

The centrifugal stretching has been ignored, as it is negligible. The effect on the value of $\left[\Delta_{2} F(J)-\right.$ $\left.3.5\left(J+\frac{1}{2}\right)\right] /\left(J+\frac{1}{2}\right)$ would be equal to $8\left(J+\frac{1}{2}\right)^{3} D$, where $D=4 B^{3}\left(\delta_{1} / \omega_{1}^{2}+\delta_{2} / \omega_{2}^{2}\right)$ and - where $\delta_{1}^{2}+\delta_{2}^{2}=1 .^{6}$ The largest possible value of $D$ would be for $\delta_{1}=0$ and $\delta_{2}=1$. Thus $D=4 \times .85^{3} \times 1 / 1760^{2} \cong 10^{-6}$, and for $J=30$, the centrifugal stretching $\leq 8 \times 27,000 \times$ $10^{-6} \cong 0.014 \mathrm{~cm}^{-1}$. This is much less than the experimental error.

Washington, March 20, 1951

${ }^{6}$ W. Schaffer and A. Nielsen, J. Chem. Phys. 9, 847 1941). 